\title{
Ectopic ovarian pregnancy following in vitro fertilization: case report
}

\author{
Shrinkhla Khandelwal*, Neeta Natu
}

Department of Obstetrics and Gynecology, Sri Aurobindo Institute of Medical Sciences, Indore, Madhya Pradesh, India

Received: 23 February 2020

Accepted: 27 March 2020

\section{*Correspondence:}

Dr. Shrinkhla Khandelwal,

E-mail: shrinkhlak243@gmail.com

Copyright: () the author(s), publisher and licensee Medip Academy. This is an open-access article distributed under the terms of the Creative Commons Attribution Non-Commercial License, which permits unrestricted non-commercial use, distribution, and reproduction in any medium, provided the original work is properly cited.

\begin{abstract}
Ovarian pregnancy is a rare form of extrauterine ectopic pregnancy. Risk factors such as reproductive treatments and infertility have been identified in recent studies. In this article, we present a case of ovarian ectopic pregnancy occurring following in vitro fertilization treatment and a fresh embryo transfer. The diagnosis of ovarian pregnancy was made during transvaginal sonography performed due to suspected ectopic pregnancy. Ovarian ectopic pregnancy is a rare clinical phenomenon. Late diagnosis and lack of appropriate intervention may have catastrophic results. Several mechanisms and risk factors are proposed, and their acknowledgment may improve early diagnosis and prevention of complications.
\end{abstract}

Keywords: Ectopic pregnancy, Ovarian pregnancy

\section{INTRODUCTION}

The Incidence of spontaneous primary ectopic ovarian pregnancy ranges from 0.5 to $3 \%$ of all the ectopic pregnancies. ${ }^{1}$ Assisted reproductive techniques increase the risk of ovarian ectopic. The incidence of ovarian ectopic pregnancy following In vitro fertilisation embryo transfer is around $0.3 \%$ and accounts for $6 \%$ of all the ectopic pregnancies post IVF-ET. ${ }^{2,3}$ Two different mechanisms can explain the occurrence of ovarian pregnancy: direct fertilization of an ovulated mature egg inside the ovary (primary, follicular fertilisation) or ectopic implantation of a fertilized embryo with retrograde migration from the endometrial cavity to the ovarian surface (secondary). ${ }^{4}$ The latter mechanism would most likely be responsible for ovarian ectopic after IVF-ET. Detecting ovarian ectopic at an early stage is challenging and in most cases the diagnosis is made during work up for acute abdominal pain or bleeding.

In this case report, study describe an ovarian pregnancy following IVF-ET.

\section{CASE REPORT}

The patient was a 32-year female with primary infertility. She and her husband had no prior medical history and underwent investigations for the infertility. Her obstetric history was G2E1 with history of previous right tubal ectopic pregnancy in 2012 managed medically. The present pregnancy was a result of embryo transfer on day 5 (3 embryos transferred) after long protocol of ovulation. Her $\beta \mathrm{Hcg}$ level was $217 \mathrm{mIU} / \mathrm{ml}$ on day 1 which doubled to 553 after 36 hours. At six weeks period of gestation she presented with pain lower abdomen. She was hemodynamically stable with normal vital parameters. Trans-vaginal sonogram demonstrated empty uterine cavity and suspicious left adnexal mass with gestational sac like structure $(7.4 \times 8.4 \times 2.9 \mathrm{~cm}$ dimension $)$ observed in the mass. Left ovary could not be visualized separate from the mass and moderate free fluid was present in the peritoneum. Her $\beta$ Hcg level was 1671 $\mathrm{mIU} / \mathrm{ml}$. A diagnosis of ruptured ectopic pregnancy was made. An exploratory laparotomy was performed shortly after and hemoperitoneum (1200 ml) was drained. 
Uterus, right ovary and bilateral fallopian tubes with their fimbrial ends were found to be healthy. Ruptured left ovarian ectopic was identified and excised from the ovary via wedge resection and the remaining tissue sutured using catgut. The operative and postoperative period was uneventful and the patient was followed with sequential $\beta$ Hcg levels till they dropped to zero. The histopathology report demonstrated ovarian tissue with the presence of trophoblastic tissue in the sample thus confirming the diagnosis.

\section{DISCUSSION}

The case presented here is a result of fresh embryo transfer. The most likely mechanism for its occurrence is retrograde migration of the blastocyst through the tube and implantation into the ovary.

Symptoms of ovarian pregnancy are similar to the symptoms of tubal pregnancy, namely, absent or delayed menses, abdominal pain and vaginal bleeding; however, asymptomatic ovarian pregnancies have also been described. ${ }^{5}$ As with other extrauterine pregnancies, an empty uterus and rising serum $\beta$ hCG should raise suspicion; however, ovarian pregnancy is rarely diagnosed before the surgery due to poor clinical symptomatology and a difficult ultrasound diagnosis. Otto Spiegelberg, a German gynecologist established the diagnostic criteria for ovarian pregnancy based on intraoperative findings: (1) intact fallopian tube on the involved side, (2) the gestational sac is located in the same position as the ovary, (3) the ectopic pregnancy is connected to the uterus by the utero-ovarian ligament, and (4) the ovarian tissue is present in the wall of the gestational sac. ${ }^{6,7}$

Several factors have been suggested which result in increased incidence of ovarian ectopic like pelvic inflammatory disease, previous gynecologic surgery, intrauterine contraceptive devices, tubal pathology. 8,9 Factors associated with extrauterine pregnancy in IVF are tubal infertility, fresh embryo transfer compared to frozen, cleavage stage compared to blastocyst stage embryos, and large number of transferred embryos. ${ }^{10,12,13}$ Injection of a high volume of transfer media and the patient in a tilted position are other possible associated factors that result in ovarian ectopic. ${ }^{14}$ Several studies suggest a possible relationship between ectopic pregnancy and high levels of serum estradiol. ${ }^{13}$ In their study, Wang et al found a higher prevalence of ectopic pregnancy following fresh embryo transfer compared to frozen embryo transfer, a sub-analysis of the results showed more ectopic pregnancies among patients with peak serum estradiol concentration exceeding 4085 $\mathrm{pg} / \mathrm{mL}(15,000 \mathrm{pmol} / \mathrm{L}){ }^{15}$

The role of imaging and serum $\beta$ Hcg levels is of limited value in ovarian pregnancy and the American Society for Reproductive Medicine recommends on a surgical intervention in such cases. ${ }^{16}$ The surgical treatment may be in the form of salpingo-oophorectomy, oophorectomy, wedge resection, and removal of gestational product. There are few reports of successful use of systemic methotrexate in ovarian pregnancy. ${ }^{17,18}$ However it should be noted that unlike the role of MTX in the treatment of tubal pregnancy, its role in the management of ovarian pregnancy is not well established.

\section{CONCLUSION}

Ovarian pregnancy is an infrequent and challenging diagnosis. Clinicians should be aware about its possible occurrence in ART treatment. Once suspected, it should be actively pursued and managed in order to prevent complications.

\section{Funding: No funding sources \\ Conflict of interest: None declared \\ Ethical approval: Not required}

\section{REFERENCES}

1. Raziel A, Golan A, Pansky M. Ovarian pregnancy: a report of twenty cases in one institution. Am J Obstet Gynecol. 1990;163:1182-5.

2. Marcus SF, Brinsden PR. Analysis of the incidence and risk factors associated with ectopic pregnancy following in-vitro fertilization and embryo transfer. Human Reprod. 1995;10(1):199-203.

3. Marcus SF, Brinsden PR. Primary ovarian pregnancy after in vitro fertilization and embryo transfer: report of seven cases. Fertil Steril. 1993;60(1):167-9.

4. Ishikawa H, Sanada M, Shozu M. Ovarian pregnancy associated with a fresh blastocyst transfer following. J Obstet Gynaecol Res. 2015;41(11):1823-5.

5. Andrade AG, Rocha S, Marques CO. Ovarian ectopic pregnancy in adolescence. Clin Case Rep. 2015;3(11):912-5.

6. Samara N, Bentov Y. Case report of ectopic ovarian pregnancy following fresh embryo transfer. Clin Med Insights Reprod Health. 2016;10:29-32.

7. Spiegelberg O. Zur casusistik der ovarial schwangerschaft. Arch Gynaekal. 1978;13:73-39.

8. Choi HJ, Im KS, Jung HJ, Lim KT, Mok JE, Kwon YS. Clinical analysis of ovarian pregnancy: a report of 49 cases. Eur J Obstet Gynecol Reprod Biol. 2011;158(1):87-9.

9. Kashima K, Yahata T, Yamaguchi M, Fujita K, Tanaka K. Ovarian pregnancy resulting from cryopreserved blastocyst transfer. J Obstet Gynaecol Res. 2013;39(1):375-7.

10. Huang B, Hu D, Qian K, Ai J, Li Y, Jin L, et al. Is frozen embryo transfer cycle associated with a significantly lower incidence of ectopic pregnancy? An analysis of more than 30,000 cycles. Fertil Steril. 2014;102(5):1345-9.

11. Shapiro BS, Daneshmand ST, De Leon L, Garner FC, Aguirre M, Hudson C. Frozen-thawed embryo transfer is associated with a significantly reduced 
incidence of ectopic pregnancy. Fertil Steril. 2012;98(6):1490-4.

12. Ishihara O, Kuwahara A, Saitoh H. Frozen-thawed blastocyst transfer reduces ectopic pregnancy risk: an analysis of single embryo transfer cycles in Japan. Fertil Steril. 2011;95(6):1966-9.

13. Bu Z, Xiong Y, Wang K, Sun Y. Risk factors for ectopic pregnancy in assisted reproductive technology: a 6-year, single-center study. Fertil Steril. 2016;106(1):90-4.

14. Atabekoglu CS, Berker B, Dunder I. Ovarian ectopic pregnancy after intracytoplasmic sperm injection. Eur J Obstet Gynecol Reprod Biol. 2004;112(1):1046.

15. Wang J, Wei Y, Diao F, Cui Y, Mao Y, Wang W, et al. The association between polycystic ovary syndrome and ectopic pregnancy after in vitro fertilization and embryo transfer. Am J Obstet Gynecol. 2013;209(2):139.e1-9.
16. Practice Committee of American Society for Reproductive Medicine. Medical treatment of ectopic pregnancy. Fertil Steril. 2006;86(5 suppl 1):S96S102.

17. Kudo M, Tanaka T, Fujimoto S. A successful treatment of left ovarian pregnancy with methotrexate. Nippon Sanka Fujinka Gakkai Zasshi. 1988;40:811-3.

18. Shamma FN, Schwartz LB. Primary ovarian pregnancy successfully treated with methotrexate. Am J Obstet Gynecol. 1992;167:1307-8.

Cite this article as: Khandelwal S, Natu N. Ectopic ovarian pregnancy following in vitro fertilization: case report. Int J Reprod Contracept Obstet Gynecol 2020;9:2174-6. 